\title{
Seed coating provides rice seeds for aerial seeding with reduced phenamacril loss and a prolonged rice seedling protection
}

\author{
Tingting Wang ${ }^{1}$, Anyu Gu${ }^{2}$, Lijie Teng ${ }^{1}$, Xiaolin Li ${ }^{2}$, Mingqi Wang ${ }^{1}$, Pengfei Liu ${ }^{1 *}$ \\ (1. College of Plant Protection, China Agricultural University, Beijing 100193, China; \\ 2. Institute of Food Crops, Yunnan Academy of Agricultural Sciences, Kunming 650205, China)
}

\begin{abstract}
Along with the increased application of unmanned aerial vehicles (UAV) in agriculture in recent years, the aerial seeding of rice has been developed and applied in China. Film-coated seeds with phenamacril have become increasingly popular for the ecological friendly prevention and control of rice seedling pests, due to their compatibility with aerial seeding methods. In this research, an analytical method for the HPLC measurement of phenamacril residue on rice seeds and seedlings has been developed. The active dose delivery of phenamacril for rice seeds and seedlings under flooding condition was studied after a seed dressing of $5 \%$ phenamacril flowable suspension (FS) and a film coating with $5 \%$ phenamacril flowable concentrate for seed coating (FSC). Results showed that the recovery rate and relative standard deviation (RSD) of phenamacril in rice seeds and seedlings were $88.31 \%$ to $107.55 \%$ and $2.54 \%$ to $9.66 \%$, respectively. Compared to FS, FSC containing $3 \%$ of binder $\# 1$ and \#11 significantly increased phenamacril residue during seed soaking for $48 \mathrm{~h}$ from $59.91 \mathrm{mg} / \mathrm{kg}$ to 88.47 and $88.69 \mathrm{mg} / \mathrm{kg}$, which were even better than $5 \%$ or $8 \%$ binders used. There was no significant difference between either FSC treatment when the concentration of binder was the same, and the protection duration of phenamacril by film coating, with $3 \%$ of binder \#11 used, extended to $40 \mathrm{~d}$ after sowing. This study showed that a coating treatment of rice seeds could effectively reduce the loss of phenamacril under flooding conditions, making it a promising seed treatment method for use in direct seeding by airplane operations.
\end{abstract}

Keywords: binder, seed coating, HPLC, uptake, phenamacril

DOI: $10.33440 /$ j.jppaa.20210401.150

Citation: Wang T T, Gu A Y, Teng L J, Li X L, Wang M Q, Liu P F. Seed coating provides rice seeds for aerial seeding with reduced phenamacril loss and a prolonged rice seedling protection. Int J Precis Agric Aviat, 2021; 4(1): 70-74.

\section{Introduction}

Rice is one of the important grain crops widely cultivated in China, however, its level of mechanized operation is still in the early stage of development. The renewal and reform of mechanical sowing of rice plays an important role in promoting the development of the comprehensive mechanization of rice. Compared with manual rice seedling propagation and transplantation, unmanned aerial vehicle (UAV) rice seeding technology has the advantages of low cost, high operation efficiency, high intelligence, low labor intensity, labor saving, and suitability for large-scale operations ${ }^{[1,2]}$. These benefits are why UAV rice seeding technology has been gradually applied for precision rice seeding in recent years. Meanwhile, UAV rice seeding in paddy land also poses a new challenge to the long-term use of seed dressing to prevent and control rice seedling disease ${ }^{[3]}$.

As an important plant protection measure to realize seed commercialization and standardization, seed film-coating is the practice of covering seeds with external materials to improve

\section{Received date: $2021-02-27$ Accepted date: $2021-03-28$}

Biography: Tingting Wang, Master student, chemical control of crop diseases, Email: wtt104823@163.com; Anyu Gu, seed science and seed treatment technology, Email: 897821051@qq.com; Lijie Teng, Master student, chemical control of crop diseases, Email: tenglijie@126.com; Xiaolin Li, PhD, seed science and seed treatment technology, Email: xiaolinli@163.com; Mingqi Wang, Master, chemical control of crop diseases, Email: wangmingqi1310@126.com.

* Corresponding author: Pengfei Liu, PhD, research interests: seed treatment technology and chemical control of crop diseases. No. 2, Yuanmingyuan West Road, Haidian District, Beijing. Email: pengfeiliu@cau.edu.cn. protection, and, to a lesser extent, germination enhancement and plant establishment ${ }^{[4]}$. It has been widely used in dryland $d^{[5,6]}$. The main cultivation process of rice planting includes seed soaking, germination, and rice seedling propagation, so it is particularly important to use a water proof binder in FSC to maintain the pesticides on the seeds for paddy field. Due to obstacles in the popularization and application of rice direct seeding technology and the development and promotion of rice seed film-forming technologies, only $16.25 \%$ of seed film coating products were registered for rice in $2019^{[7-9]}$. However, with the popularization of the pesticide application strategy of reducing the amount of pesticides required and increasing the efficiency of disease control effect in recent years, rice seed film coating technology, as an important disease prevention and control technology for seedlings, has been continuously and rapidly improved and developed, because of its high environmental safety and effectiveness when applied to seeds. Rice bakanae disease, rice thrips and rice planthopper are important control objects of rice seed film coating agent registration $^{[10-12]}$.

Phenamacril, developed by Jiangsu Pesticide Research Institute Co.Ltd, has been used to control rice bakanae disease caused by Fusarium fujikuroi ${ }^{[13]}$, strawberry wilt caused by Fusarium oxysporum $^{[14]}$ and wheat scab caused by Fusarium graminearum together with other Fusarium species ${ }^{[15]}$. In rice bakanae disease control, phenamacril has been registered as the formulation of flowable suspension with application methods of seed soaking and seed coating (http://www.chinapesticide.org.cn/).

Due to the special waterlogged growing environment of rice, the binder for rice seed film coating needs to have higher water 
resistance and air permeability than that for dry crop seeds in order to reduce the loss of pesticide effect and successfully improve the quality of seedlings ${ }^{[16,17]}$. However, the commonly used film-forming substances such as polyvinyl alcohol, chitosan, or their blend products are highly soluble in water ${ }^{[18-20]}$, making it impossible to maintain a sufficient concentration of the active ingredient to ensure prophylactic activity. The effects of seed dressing and seed film coating agents containing binder \#1 and binder \#11 on the persistence of phenamacril were studied in this paper in order to produce data for the scientific application of rice seed coating technology in pest control and for an evaluation of UAV rice-seeding.

\section{Materials and Methods}

\subsection{Materials}

Rice seeds (Jiafuzhan) were obtained from commercialized. Phenamacril (a.i. 93.4\%) and phenamacril flowable suspension (FS) for seed dressing (25\%) was purchased from Jiangsu Research Institute Co., Ltd (Jiangsu, China). The polyvinyl alcohol binder $\# 1$ and styrene-acrylic emulsion binder \#11 were prepared in our laboratory. Phenamacril FS (5\%) with 5\% red dye was prepared by diluting $25 \%$ phenamacril FS. The FSC with $5 \%$ phenamacril, $5 \%$ red dye, and $3 \%, 5 \%$, or $8 \%$ binder \#1 or \#11 were also prepared Methanol (HPLC grade), and acetonitrile (HPLC grade) were purchased from Thermo Fisher Scientific Shier Technology Co., Ltd (Beijing, China). Anhydrous sodium acetate and anhydrous sodium acetate were purchased from Sinopharm Chemical Reagent Co., Ltd (Beijing, China). Deionized water was used for the entire experiment, and ultrapure water $[18.2 \mathrm{M} \Omega \mathrm{cm}$, total organic carbon $(\mathrm{TOC}) \leq 4 \mathrm{ppb}]$, obtained from a Milli-QAdvantage A10 system (Millipore, Milford, MA, USA), was used for high-performance liquid chromatography (HPLC) analysis. High performance liquid chromatograph (Model Agilent 1100, agilent company, USA), medical ultrasonic cleaner (Model KQ-250E, kunshan ultrasonic instrument co., ltd, kunshan, China), DFT-100100 portable high-speed universal crusher, and DH6000 electrothermal constant temperature incubator, $0.22 \mu \mathrm{m}$ filter membrane were used.

\subsection{Seed treatment}

Phenamacril 5\% FS and FSC were diluted to 4\% active ingredient for seed dressing and film coating respectively to a ratio of 1:40 by weight of phenamacril liquid to seed, and the theoretical amount of the fungicide coated on the seeds surface was $100 \mathrm{mg} / \mathrm{kg}$. The treated seeds were soaked with $1.2 \times$ deionized water for $48 \mathrm{~h}$ to acquire plenty of moisture for later germination, followed by phenamacril concentration detection by HPLC after drying at $25^{\circ} \mathrm{C}$ for $12 \mathrm{~h}$. Then the phenamacril concentration $(\mathrm{mg} / \mathrm{kg})$ in seeds were detected by HPLC, and the loss rates of phenamacril (\%) were calculated by minus detection concentration from the original coated phenamacril $(100 \mathrm{mg} / \mathrm{kg})$ on seeds and then divided by it.

$$
\text { Loss rate }=100 \% \times(100-\text { detection concentration }) / 100
$$

\subsection{Degradation dynamics of chemicals in rice seedlings}

Seeds were germinated for 3 days, and then sown in flooded soil. The concentration of phenamacril was detected and analyzed by HPLC using extracted components from rice seedlings on day 3 (germination), 6, 8, 10, 13, 18, and 28.

\subsection{Sample pretreatment}

In the first step of sample pretreatment, seeds were ground into powder with a universal pulverizer, while roots of rice seedlings, after absorbing surface moisture, were flash frozen with liquid nitrogen and ground into powder. Three grams of the powder was weighed in a centrifuge tube. Three milliliters of deionized water was added and mixed evenly. Samples were then vortexed for $1 \mathrm{~min}$ after adding $3 \mathrm{ml}$ of $1 \%$ acetonitrile acetate. Next, $1.2 \mathrm{~g}$ anhydrous magnesium sulfate and $0.3 \mathrm{~g}$ anhydrous sodium acetate were added. The obtained mixture was swirled for $1 \mathrm{~min}$ and centrifuged for $10 \mathrm{~min}$ at $4000 \mathrm{r} / \mathrm{min}$. One milliliter of the organic phase of the mixture was transplanted to a new centrifuge tube with $0.15 \mathrm{~g}$ of anhydrous magnesium sulfate added. Finally, the supernatant was centrifuged and filtered with a $0.22 \mu \mathrm{m}$ filter membrane.

\subsection{Preparation of standard solutions}

Phenamacril was weighed and dissolved in methanol by ultrasonic dissolution to a final concentration of $1000 \mu \mathrm{g} / \mathrm{mL}$. This concentrated solution was further diluted into standard working solutions at concentrations of $0.4,2,5,10,15,25,40,100 \mu \mathrm{g} / \mathrm{mL}$ to be detected by HPLC after being added to solutions extracted from seeds and plants without treatment.

\subsection{Methodological review}

Three levels of pharmaceutical standard solutions were added to $3 \mathrm{~g}$ of blank seed matrix and blank rice seedling matrix, which were then used for HPLC detection and analysis after pretreatment. The recovery rate was determined by three repetitions and the precision of the method was determined by five repetitions.

\subsection{HPLC analysis}

Ultraviolet detection wavelength: $290 \mathrm{~nm}$

Column temperature: $35^{\circ} \mathrm{C}$

Flow rate: $1 \mathrm{~mL} / \mathrm{min}$

Mobile phase: methanol: water $=48: 52$

Sample injection volume: $10 \mu \mathrm{L}$.

\subsection{Data analysis}

The degradation dynamic curve of phenamacril was fitted by first order dynamic equation and the degradation half-life was calculated by exponential regression equation according to the test results, the calculation formula is as follows:

$$
C_{T}=C_{0} \mathrm{e}^{-K T} ; \quad T_{1 / 2}=\ln 2 / K
$$

where, $C_{T}$ - the phenamacril residue at time $T(\mathrm{~d}$ or h), and the unit is $\mathrm{mg} / \mathrm{kg} ; C_{0}$ - the original deposition amount after application, and the unit is $\mathrm{mg} / \mathrm{kg} ; K$ - digestion coefficient; $T$ - time after application, in days(d); $T_{1 / 2}$ - digestion half-life, in days(d).

\section{Results}

\subsection{Method specificity analysis}

\subsubsection{The Matrix Standard Curve}

Gradient standard solutions of phenamacril were obtained by adding phenamacril standard into blank seed matrix and blank rice seedling matrix and injecting from low to high concentration continuously. The mass concentration of the standard solution $(\mu \mathrm{g} / \mathrm{mL})$ was taken as the abscissa and the measured peak area (mAU.S) of the parent compound was taken as the ordinate. The results are shown in Figure 1. The linear regression equation obtained from the standard curve were $y=41.106 x-2.7224\left(r^{2}=\right.$ $0.9995)$ of blank seed matrix and $y=45.739 x-26.764\left(R^{2}=0.9994\right)$ of blank rice seedling matrix. The results showed that a linear correlation existed between peak area and concentration in the range of $0.4-100 \mu \mathrm{g} / \mathrm{mL}$.

3.1.2 The determination of increased recovery rate and precision

Recovery rate is shown in Table 1. The table illustrates the upper recovery rate of this method, ranging from $88 \%$ to $107 \%$, and desirable stability, RSD $\leq 10 \%$, which met the requirements of trace determination of phenamacril in rice seeds and seedlings. 


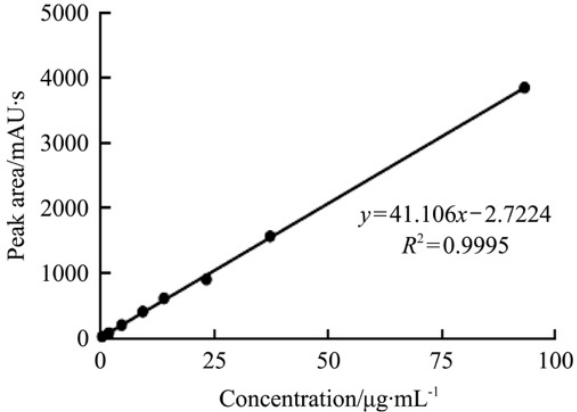

a.

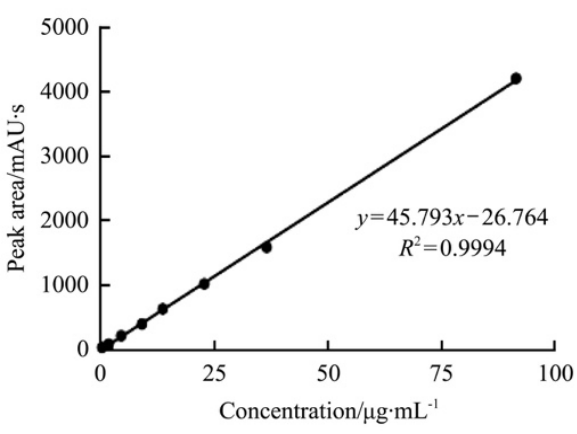

b.

Figure 1 The standard curve for phenamacril trace analysis in rice seeds sample (a) and rice seedlings sample (b)

Table 1 Recovery rate and relative standard deviation $(n=5)$ of phenamacril in rice seeds and seedlings

\begin{tabular}{ccccc}
\hline $\begin{array}{c}\text { Type of } \\
\text { sample }\end{array}$ & $\begin{array}{c}\text { Added concentration } \\
\text { of phenamacril } \\
/ \mathrm{mg}^{\mathrm{kg}} \mathrm{kg}^{-1}\end{array}$ & $\begin{array}{c}\text { Detection } \\
\text { concentration } \\
/ \mathrm{mg}^{-1} \mathrm{~kg}^{-1}\end{array}$ & $\begin{array}{c}\text { Percent } \\
\text { recovery } \\
/ \%\end{array}$ & $\begin{array}{c}\text { Relative } \\
\text { standard } \\
\text { deviation} / \%\end{array}$ \\
\hline $\begin{array}{c}\text { Rice } \\
\text { seedlings }\end{array}$ & 1 & $1.04 \pm 0.03$ & 104.07 & 3.03 \\
\hline & 5 & $5.38 \pm 0.44$ & 107.55 & 8.20 \\
Rice seeds & 15 & $14.36 \pm 0.36$ & 95.74 & 2.54 \\
& 5 & $0.89 \pm 0.04$ & 88.65 & 4.26 \\
\hline
\end{tabular}

\subsection{Analysis of chemical loss of different seed treatment methods}

The difference in loss of phenamacril between rice seed film coating and seed dressing is shown in Table 2. It can be seen that rice seeds soaked for $48 \mathrm{~h}$ after seed dressing contained $59.91 \mathrm{mg} / \mathrm{kg}$ of phenamacril, with the highest recorded phenamacril loss rate of $40.09 \%$. After being coated with FSC containing binder \#11 and soaked for $48 \mathrm{~h}$, the content of phenamacril was $76.52 \sim 88.69 \mathrm{mg} / \mathrm{kg}$, and the loss rate was $11.31 \% \sim 23.48 \%$. The phenamacril loss was slightly lower than that of the FSC containing binder $\# 1$, and there was no significant difference when the concentration of the binder was the same. However, compared with the seed dressing, the seed film coating significantly reduced the loss rate, which was only between $11.31 \%$ and $28.38 \%$.

Table 2 Phenamacril concentration in rice seeds after soaking for $48 \mathrm{~h}$

\begin{tabular}{ccc}
\hline Treatment & $\begin{array}{c}\text { Detection concentration } \\
/ \mathrm{mg} \cdot \mathrm{kg}^{-1}\end{array}$ & $\begin{array}{c}\text { Loss rate of } \\
\text { phenamacril/\% }\end{array}$ \\
\hline Seed dressing & $59.91 \pm 2.60 \mathrm{c}$ & $40.09 \mathrm{a}$ \\
Seed coating with 3\% of binder \#1 & $88.47 \pm 5.20 \mathrm{a}$ & $11.53 \mathrm{c}$ \\
Seed coating with 5\% of binder \#1 & $76.28 \pm 1.73 \mathrm{~b}$ & $23.72 \mathrm{~b}$ \\
Seed coating with 8\% of binder \#1 & $71.62 \pm 7.26 \mathrm{~b}$ & $28.38 \mathrm{~b}$ \\
Seed coating with 3\% of binder \#11 & $88.69 \pm 3.15 \mathrm{a}$ & $11.31 \mathrm{c}$ \\
Seed coating with 5\% of binder \#11 & $77.53 \pm 5.07 \mathrm{~b}$ & $22.47 \mathrm{~b}$ \\
Seed coating with 8\% of binder \#11 & $76.52 \pm 3.69 \mathrm{~b}$ & $23.48 \mathrm{~b}$ \\
\hline
\end{tabular}

In this test, we found that the film formed by binder \#1 was disrupted and disassociated from the seed surface, with the seed soaking water becoming cloudy red (Figure 2). But the seed soaking water treated by binder \#11 was completely colorless and transparent. This may have something to do with binder \#1 being a polyvinyl alcohol binder, which forms film with a relative higher water absorption ability, relatively poor in water resistance and easy to disassociate when in water than styrene-acrylic emulsion binder ${ }^{[13,21,22]}$, resulting in phenamacril loss, while the binder \#11 is a styrene-acrylic emulsion binder, which has superior water resistance and is more suitable for a paddy field. However, no significant difference appeared in phenamacril loss between treatment with the two kinds of binders. We speculate that the reason for this phenomenon was that although the binder \#1 had poor water resistance and more easily peeled off from the seed surface while in water, the seeds could still absorb most of the phenamacril from the relatively small amount of water in the experimental conditions. However, in a paddy field with a large volume of water, the concentration of phenamacril is diluted, which is likely to cause a high loss rate of phenamacril. In addition, when the concentration of binder was between $3 \% \sim 8 \%$, the concentration of binder was negatively correlated with the concentration of phenamacril of seeds soaked after coating. It was speculated that there were two possibilities: one might be the adhesion of phenamacril to the inner wall of the coated Petri dish caused by superabundant binders; another possibility was that the increase of binder dose led to the thickening of the phenamacril film on the seed surface, which made the film crack open and peel off more readily. This phenomenon has been observed in previous research in styrene-acrylic emulsion ${ }^{[23]}$. The mechanical properties increased with the increase of PVA content, however decreased when the content was above $2.2 \%$. PVA was considered no longer played the role of protective adhesive, but acted as a "flocculant" seed in the synthesis of polymer emulsion, resulting in gel particles produced in the synthesis of polymer emulsion with this PVA content, thus greatly reducing the comprehensive mechanical properties of polymer emulsion film.

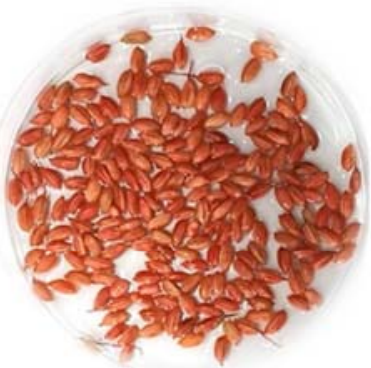

a. Before

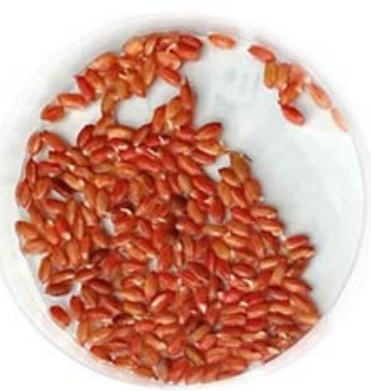

a. After

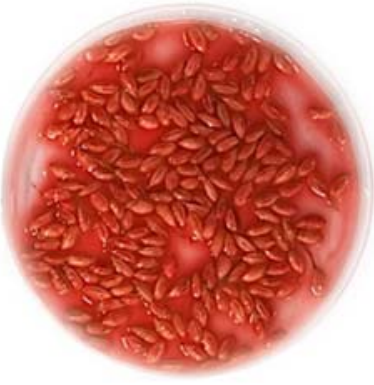

b. Before

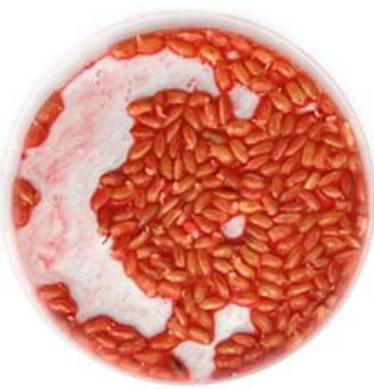

b. After
Figure 2 Seed film coating of rice with $5 \%$ phenamacril FSC containing binder \#11 (a) or binder \#1 (b) before and after being soaked in water for $48 \mathrm{~h}$ 


\subsection{Degradation Dynamics of Phenamacril in Rice}

The formulation $5 \%$ phenamacril FSC containing 3\% of binder \#11 was used to coat seeds, and 5\% phenamacril FS without binder was used to dress seeds. Both treated seeds and rice seedlings were collected from 0 to $28 \mathrm{~d}(0 \mathrm{~d}$ means before germinating and after soaking seeds for 48 hours) and analyzed for residual amounts of phenamacril by HPLC, germinating for 3 days and planting in flooded soil. Figure 3 shows the degradation of phenamacril in rice seeds and seedlings after seed dressing or film coating. The attenuation trend of effective components was basically the same, showing a tendency of fast at first and then slow.

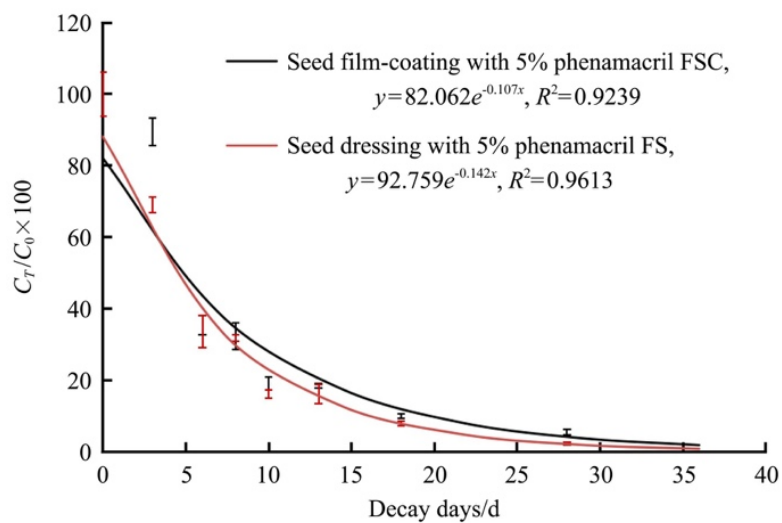

Figure 3 Degradation dynamics of phenamacril in rice plants with the treatment of seed dressing or film coating $(0 \mathrm{~d}$ means before germinating and after soaking seeds for $48 \mathrm{~h}$ )

The degradation kinetic equation of the phenamacril, with seed film coating, in rice plants was $y=82.062 \mathrm{e}^{-0.107 x}, R^{2}=0.9239, k=$ 0.107 , which accorded with the first-order kinetic equation. The half-life of degradation of phenamacril was $t_{1 / 2}=6.48 \mathrm{~d}$, and the phenamacril residue was $2.48 \mathrm{mg} / \mathrm{kg}$ after $28 \mathrm{~d}$. With the treatment of seed dressing, the kinetic equation of phenamacril degradation was $y=92.759 \mathrm{e}^{-0.142 x}, R^{2}=0.9613, k=0.142$, and the half-life was $t_{1 / 2}=4.89 \mathrm{~d}$. In addition, the phenamacril residue on seedling surfaces after $28 \mathrm{~d}$ was $1.39 \mathrm{mg} / \mathrm{kg}$. This indicates that the half-life period of phenamacril in rice plants was longer with the film coating treatment, compared to the seed dressing treatment.

According to the literature ${ }^{[24]}$, the $\mathrm{EC}_{90}$ of phenamacril on the hyphae growth of Fusarium fujikuroi, the pathogen of rice bakanae disease, is $0.49 \mu \mathrm{g} / \mathrm{mL}$. After application for 28 days, the contents of the phenamacril in rice plants are still sufficient to main the control effect on rice bakanae disease. Furthermore, according to the kinetic equation of the degradation, we can predict that phenamacril residue will remain at the $\mathrm{EC}_{90}$ value and therefore capable of effectively controlling rice bakanae disease after $33.6 \mathrm{~d}$ with seed dressing and $40.3 \mathrm{~d}$ with seed film coating. The phenamacril residue in seed coating treatment was higher than that in seed dressing treatment, which indicated that seed coating treatment could provide a longer efficacy duration for disease control of rice seedling.

\section{Conclusions}

For the simple, rapid, accurate, and economical detection of phenamacril, we developed a QuEChERS-HPLC method for the determination of phenamacril residue concentration in rice seeds and seedlings, and analyzed the degradation dynamics of phenamacril in rice seeds and seedlings. Coating rice seeds with binders \#1 or \#11 can effectively reduce the loss rate of phenamacril during rice seed soaking. Further, we confirmed that seed coating treatment can maintain high concentrations of phenamacril, enhance the slow-release characteristics, and also improve the effective delivery amount of phenamacril in plants. In addition, the degradation dynamics of phenamacril in rice plants was proved to be in accordance with the first-order kinetic equation, and the efficacy duration on the control of rice bakanae disease can reach $40.3 \mathrm{~d}$.

HPLC was used to directly detect the amount of phenamacril and the persistence of phenamacril when rice seeds were treated differently and then soaked (simulated flooding conditions in paddy field). The differences between different seed treatment technologies were clarified, which provides data for the dissemination of rice seed film coating technology. However, the abrasion resistance and fluidity of the film coatings on seeds haven't been further studied. The experimental results of reduced chemical loss and extended efficacy period after seed film coating and soaking treatments also show the feasibility of combining rice seed film coating with UAV seeding in rice planting, and provides guidance for the renewal of rice aerial seeding technology.

\section{Acknowledgments}

This work was funded by Yunnan Main Grain Crop Seed Industry Innovation Platform and Large-scale Green Production System Construction, and Study and Demonstration of Rice Varieties Breeding and Seed Quality Control Technology (2018ZG008).

\section{[References]}

[1] Yue J, Yang X L, Li C L, et al. Research on the aplication of precision seeding technology based on UAV platform in rice direct seeding. Sichuan Agricultural Science and Technology, 2019; (04): 19-20.

[2] Diao Y, Zhu C H, Ren D H, et al. Key points and prospect of rice direct broadcast technology by unmanned aerial vehicle. Rice in China, 2020; 26(05): 22-25.

[3] Zhao G Q. What is the difference between crop seed coating and seed dressing with pesticide. Pesticide Market Information, 2017; (21): 62.

[4] Pedrini S, Merritt DJ, Stevens J, Dixon K. Seed coating: science or marketing spin? trends in plant science. 2017; 22(2): 106-116. doi: 10.1016/j.tplants.2016.11.002

[5] Coninck E, Scauflaire J, Gollier M, et al. Trichoderma atroviride as a promising biocontrol agent in seed coating for reducing fusarium damping-off on maize. Journal of Applied Microbiology, 2020; 129: 637-651. doi: 10.1111/jam.14641

[6] Zhang H Z, Xiao J Q. Study on the characteristics and application of rice seed coating technology. Seed Science and Technology, 2018; 36(06): 37.

[7] Zhao Y J. Analysis of rice seed cultivation and coating technology. Science and Technology Information, 2018; (14): 311.

[8] Editorial Department of "10 Days of Agrochemical Market News". Rice seed coating agent: great development potential is expected to usher in spring. 10 Days of Agrochemical Market News, 2019; (11): 25-28.

[9] Wu P C, Lu Y C. Seed coating technology and its application. Seed Science and Technology, 2020; 38(12): 78-80.

[10] Chen L B, Zhang J Y, Ma Y L. Study on the control effect of four seed soaking agents on rice bakanae disease. Modern Agriculture, 2016; (04): $15-16$.

[11] Fu R T, Chen C, Wang J, et al. Discussion on rice seed treatment technology to control diseases and insect pests. Sichuan Agricultural Science and Technology, 2018; (05): 34-35.

[12] Hou Y P, Qu X P,Mao X W, et al. Resistance mechanism of Fusarium fujikuroi to phenamacril in the field. Pest Management Science, 2018; 74(3): 607-616. doi: 10.1002/ps.4742

[13] Wang Z Y. Integrated control technology of common diseases and pests in rice seedling stage. Agriculture and Technology, 2020; 40(02): 114-115.

[14] Borrero C, Bascón J, Gallardo M, et al. New foci of strawberry fusarium wilt in huelva (spain) and susceptibility of the most commonly used cultivars. Scientia Horticultural, 2017; 226: 85-90. doi:: 10.1016/ j.scienta.2017.08.034

[15] Zhao S L, Wan L S, Sun H Q, et al. Resistance and control effect of different wheat varieties and fungicides to Fusarium graminearum. Barley and Cereals Science, 2018; 35(6): 40-45. 
[16] Shigehiro H, Masahiko H, Seiji O. Soybean seeds surface-coated with depolymerised chitins: chitinase activity as a predictive index for the harvest of beans in field culture. Journal of the Science of Food and Agriculture, 2001; 81(2): 205-209. https://doi.org/10.1002/1097-0010(20010115) 81:2<205::AID-JSFA798>3.0.CO;2-P

[17] Zeng D, Shi Y. Preparation and application of a novel environmentally friendly organic seed coating for rice. Journal of the Science of Food and Agriculture, 2009; 89(13): 2181-2185. doi: 10.1002/jsfa.3700

[18] Qi L, Wang Y X, Wang N, et al. Research progress of film-forming additives for rice seed coating agent. Seeds, 2017; 36(06): 54-60.

[19] Chang X C. Study on film-forming effect of chitosan in suspension seed coating agent. Modern Agricultural Science and Technology, 2016; (24): $107-108$
[20] Pan L G, Zhou W W, Ye H Y, et al. Study on the performance of polyvinyl alcohol blend modified film as binder of phenamacril seed coating agent. Journal of Pesticide Science, 2005; (02): 160-164.

[21] Chun S L, Li Y F, Lu C. Preparation of polyvinyl alcohol/waterborne polyurethane blend film. Packaging Engineering, 2020; 41(13): 145-153..

[22] Huang S T, He B, Han L, et al. Preparation of Styrene-acrylic Emulsion and its application to paper sizing. Guangdong Chemical Industry, 2018; 45(20): 24-26.

[23] Zhang D J, Li Y T, Zhang X T, et al. Preparation and Properties of High Viscosity styrene-acrylic emulsion. Applied Chemical Engineering, 2017; 46(02): 245-248

[24] Qiu Y, Li H Y, Zhang H Y, et al. Inhibitory effects of different chemicals on rice bakanae disease. China Plant Protection, 2020; 40(11): 69-72. 